\title{
Men, Mental Health and Elite Sport: a Narrative Review
}

\author{
Gary Souter $^{1 *}$ (D) Robin Lewis ${ }^{2}$ and Laura Serrant ${ }^{3}$
}

\begin{abstract}
Mental health in elite sport is receiving more publicity due to an increase in male athletes sharing their personal experiences. Sports injury is recognised as the major risk factor for psychological distress amongst male athletes, although anecdotally this may be that athletes are more likely to discuss their emotional wellbeing when related to the injury they are experiencing. Stress can be amplified within elite sport and the pressure they experience in relation to competition and performance can be exacerbated by adverse life events. This ongoing stress does not end when their sporting career does, it can follow them into retirement. The physical and psychological demands placed upon them by the sporting environment may predispose athletes to developing depression. As an athlete's symptoms of mental illness intensify, their performance can be negatively affected leaving them vulnerable and exposed to further symptoms of common mental disorders. The pressure of performance can also expose male athletes to overtraining syndrome which can be difficult to distinguish from depression. Male athletes are more vulnerable to eating disorders compared with males in the general population and they do have anxieties, particularly around their bodies, but find it difficult to disclose their concerns. In addition to this, male athletes are more likely to use substances, including opioids to improve both sport and non-sport performance.

Despite the prevalence of common mental disorders in male athletes, stigma still exists, and although some athletes discuss their issues publicly after their career has ended, the majority of athletes prefer to remain silent. There remains a view that athletes who seek help for psychological problems may be seen as weak. Although there is an improvement in help-seeking attitudes within elite sport, further research and education is needed to encourage men to talk about their mental health, share their experiences and to enjoy a greater sense of emotional wellbeing.
\end{abstract}

Keywords: Male, Mental health, Elite performance, Depression, Stress, Injury

\section{Key points}

- Major negative life events, including injury, may increase the risk of mental ill-health in elite athletes.

- Male athletes need to be encouraged to discuss their emotions, concerns and anxieties.

- There should be further education and awareness of mental health issues aimed at elite male athletes.

\section{Background}

Professional sportsmen are recognised for the stress and strain that they put their bodies through and it is

\footnotetext{
* Correspondence: g.souter@shu.ac.uk

${ }^{1}$ Sheffield Hallam University, Faculty of Health \& Wellbeing, F426 Robert

Winston Building, 11-15 Broomhall Road, Sheffield S10 2BP, UK

Full list of author information is available at the end of the article
}

widely accepted that they will encounter physical injury at some point. There is a societal view that sport is about winning and competing, and the focus is predominantly about individual or team performance. Male athletes can be viewed as superhuman and the impact of their emotional wellbeing is frequently overlooked. Mental health in elite sport is receiving more publicity due to an increase in male athletes sharing their personal experiences. The fields of sports psychology and sports psychiatry are rapidly developing areas aimed at understanding, diagnosing, treating and rehabilitating athletes. Sport psychology focuses upon the use of mental skills training within the sporting domain [1] and sports psychiatry aims to optimise the health of athletes, improve athletic performance, as well as managing psychiatric symptoms or disorders of athletes [2]. 
The aim of this review is to explore the issues affecting men, and their mental health in the context of elite sport.

The term mental health encapsulates a wide variety of meanings. Mental health can be seen in both a positive and negative light. Mental ill health covers a range of disorders and diagnoses many of which can have a debilitating impact on the sufferer. In contrast to this, mental wellbeing can be defined as when an individual realises his or her own potential, can cope with the normal stresses of life, can work productively and fruitfully and is able to make a contribution to her or his community [3]. One in four people in the UK will be affected by mental illness in any year with the most common being depression and anxiety [3]. Common mental disorders include depression, generalised anxiety disorder, panic disorder, phobias, social anxiety disorder, obsessive-compulsive disorder and post-traumatic stress disorder [4]. For the purpose of this review, the focus will be based on the following areas; injury, stress, depression, anxiety, overtraining, disordered eating, substance abuse, help seeking and mental toughness.

\section{Main Text \\ Injury}

One of the most recognised risk factors for psychological distress amongst male athletes has been sports injury [5]. Major negative life events, including injury, may increase the risk of mental ill-health in elite athletes [6]. Injuries are particularly found to be associated with depression in athletes [7]. Symptoms of common mental disorders amongst both current and former athletes, including depression and anxiety, were found to be related to several determinants, particularly injury [8], and former athletes who had suffered from several severe injuries or surgeries were 2-7 times more likely to report symptoms of common mental disorders than former athletes without injury or surgery. Injured athletes have higher depression scores than non-injured athletes [7]. This may be due to the view that injured athletes are more likely to discuss their emotions related to the injury they are experiencing. It is suggested that professional footballers who had sustained one or more severe joint injuries during their career were three to four times more likely to report distress compared to footballers who had not suffered from severe joint injuries during their career [9]. Athletes suffer from a higher risk of injuries and $80 \%$ of the time, athletes attending for treatment on their injury also discussed their psychological issues caused by the injury [5]. In a focus group study, negative emotions such as depression, sadness and anger were potential outcomes for both short- and long-term injuries [10].

It is also worth considering the risk of head injuries and the link between head injuries and depression [10].
The concern of head injuries and particularly concussion is a topic of continuing debate in the United States (US). The National Football League (NFL) players regularly experience repeated trauma to their heads during each match they play. The limitations of this research need to be acknowledged as the evidence includes self-reports and self-selecting samples. There is a significant relationship between the number of self-reported concussions and self-reported depressive symptoms in retired NFL players [11]. Concussion and multiple brain injuries can be related to depression [12, 13]. Former NFL players took legal action against the NFL due to concerns that repeated head injuries and concussion were causing chronic traumatic encephalopathy (CTE) which can only be diagnosed after death. A study found that $99 \%$ of professional NFL athletes had a disease associated with head injuries [14]. Out of a sample of 202 players, $87 \%$ were found to have traces of CTE. Although these results need to be viewed with caution as the brains of the sample were donated by concerned family members, however the awareness of the impact of head injuries and the link to depression, Alzheimer's disease and CTE is certainly on the increase. Whatever the type or cause of sport injury and the physical impact it will have on the athlete, it will evidently serve as a psychological stressor for the athlete [15] .

\section{Stress}

A professional sports career can include in excess of 640 stressors that may induce common mental disorders [16]. Even if mental ill health was evident prior to involvement in sport, it may become amplified when athletes are faced with the stressors that are associated with elite sports [17]. Within elite sport, athletes face an extreme load of physical training and psychological stress [15]. There is a need to consider competition-induced stress either prior, during or immediately after competition [18], and include factors of an athlete's sporting life including training, rehabilitation, team meetings and contract negotiations. Professional sportsmen are not immune from stress. They are vulnerable to professionspecific stressors as well as life events similar to the general population. The stress players experience does not end when their playing career does, it follows them into retirement. For example, retired professional footballers are as likely as anyone to be exposed to stressors especially major life events [9].

Retirement is a major life event that can have a significant impact when an athlete's career is over. This can result in changes to an athlete's interpersonal relationships, roles and daily routines. Athletes experience conflict in relation to deciding to continue in or retire from their sport and whether this would alleviate their 
depressive symptoms. They can develop feelings of worthlessness, and a mentality of cannot live with it, cannot live without it [19]. Career termination from elite sport has been associated with maladaptive coping strategies, depression, anxiety, increased hostility and anger and substance abuse [5]. Athletes who transition from active sport to retirement can experience a loss of identity, social networks and public identity [20]. Frequently, athletes do not recognise the impact of retirement until they are going through the process and involuntary career termination, such as injury, is more likely to have a negative impact upon an athlete's mental health compared to voluntary career termination, which is a personal decision to retire [5]. There appears to be an unwillingness amongst younger athletes and those who perceive themselves to have a significant amount of time before they retire to develop concrete plans about their future career prior to their retirement [21]. Athletes with high levels of athletic identity will derive greater satisfaction from the athletic aspects of their lives [22], although athletes going into retirement with high levels of athletic identity are likely to experience adjustment problems [23]. Athletes who maintain a strong athletic identity up to the point of retirement may be vulnerable to career transition difficulties [24], and athletes whose identity is based on participation and success in sport are more vulnerable to psychological issues such as depression [25].

An autobiographic study of top level athletes found that several of the athletes reported external stressors including bereavement, family health concerns, relationship breakdown and multiple injuries [19]. Internal stressors such as self-loathing, social anxiety and self-criticism were also reported. Life stressors were also common in a study looking at suicide amongst test cricketers [26]. Health concerns, relationship breakdown and financial difficulties were cited as being external factors. The same study highlights that there have not been any suicides amongst test cricketers since 1998. This could be attributed to the fact that professional cricket has developed a culture where players are encouraged to seek support for the stress they endure, although mental health issues are still prevalent within cricket. The Professional Cricketer's Association (PCA) have a benevolent fund and wealth of resources to support their members with any issues that they may experience [27]. There is a high prevalence of up to $38 \%$ for common mental disorders amongst current professional cricketers [28]. Cricketers' career dissatisfaction led to an increase in distress and adverse life events led to reported symptoms of distress, anxiety and depression.

A study analysed sources of stress for Professional Australian Footballers [18]. Following interviews and focus groups, they identified 77 sources of stress and grouped them into 6 key themes. Two of these themes appear key in comparison to other studies. One theme regarding worries about performance expectations and standards is supported by the view that athletes experience a unique range of stressors including managing ongoing competitive pressures to perform [6], and the pressure to deliver peak performance [29]. Depressive symptoms can be related to the failure to achieve performance-related goals [30]. Another theme focused on the negative aspects of interpersonal relationships. This could relate to conflict with trainers, partners and family [15], or mistakes by teammates or a feeling of letting teammates down [31].

\section{Depression}

Athletes may be more predisposed to depression compared to the general population and suggests that this is due to the physical and psychological demands placed upon them by the sporting environment [32]. They are exposed to similar stressors as the general population with athletes experiencing bereavement, health concerns and relationship breakdowns [33]. Elite athletes are vulnerable to developing depressive symptoms due to their high status and extreme pressure that they experience [34]. Publicly evaluated performance and a perceived acceptance in an elite environment which is dependent upon results can be a vulnerability factor for depression [35]. This sport-related stress when combined with other factors including moving away from home, risk taking behaviours and disordered eating may increase the risk of athletes developing common mental disorders [10].

There are a number of factors that increase an athlete's risk of depression compared with the general population [5]. These factors include injury, termination and performance pressures. There is a significant relationship between an athlete's depressive symptoms and performance [36], and as an athlete's depressive experiences intensified, their performances were negatively affected by their symptoms [19], although sometimes other symptoms of mental disorders such as anxiety can occur before depression.

There are mixed results within the literature examining athletes and depression. In US college athletes, $21.4 \%$ of athletes self-reported clinical symptoms of depression [37], and in Australian athletes, $46.4 \%$ of athletes experienced symptoms of at least one common mental disorder including $27.2 \%$ for depression [7]. The literature confirms that depression does exist within male athletes and there are a variety of factors both related to being an athlete and also factors comparable to the general population. 


\section{Anxiety}

Anxiety in athletes can be both facilitative and debilitative. Elite athletes can view symptoms of anxiety as performance enhancing [38]. In some sports competition, anxiety is considered as normal, although athletes who experience excessive levels of competition anxiety can experience negative consequences such as impaired performance [39]. In some sports, for example cycling, pre-race anxiety is common, and anxiety can be both helpful and unhelpful to performance [40]. Competition anxiety can be linked to self-confidence and athlete's self-confidence levels can fluctuate closer to the event and depending upon the level of competition. These competitive anxiety symptoms can become habitual and ingrained within the athlete [41]. High levels of self-confidence can help to protect athletes from interpreting anxiety symptoms as debilitative and change their emotional response to a positive state [42]. Younger athletes can be more susceptible to competition anxiety and social phobia in comparison to older athletes [43]. This is supported by a study examining the prevalence of anxiety and depression in Swiss football players. They found that male under- 21 footballers had anxiety scores comparable to the general population, although footballers over 21 had significantly lower average anxiety scores [44]. In comparison, a study examining the prevalence of anxiety and depression of elite rugby league players found that the prevalence of generalised anxiety disorder symptoms ranged from 10.1 to $14.6 \%$ which is in excess of the general population rate of $5 \%$ [45].

There is evidence to suggest that athletes who have experienced concussion may be at an increased risk of anxiety symptoms. Also, elite athletes may be susceptible to concussion due to pre-existing mental health symptoms, for example preoccupation, increased distraction or emotional dysregulation [46].

\section{Overtraining}

Another factor that can significantly impact upon an athlete's mental health is overtraining, or the overtraining syndrome (OTS). This is where the human body attempts to cope with physiological and other stressors including physical training, sleep loss, exposure to environmental stresses (e.g., exposure to heat, high humidity, cold, high altitude), occupational pressures, change of residence and interpersonal difficulties [47]. OTS can be difficult to distinguish from depression as some of the symptoms such as fatigue, insomnia, appetite change, weight loss, lack of motivation and concentration difficulties overlap with each other [48]. OTS can occur when an athlete undergoes a rigorous training schedule and has an insufficient recovery period caused through other sources of non-training stress.
Overtraining is a staleness in which athletes do not recover from previous exhaustion despite a recovery period of at least 2 weeks [15]. This may lead to maladaptive responses and in turn have a significant impact upon performance [49]. The prevalence of overtraining in elite athletes has been reported at between 20 and $60 \%$ and distance runners are the most severely affected [50]. An athlete's addictive behaviour may be responsible for OTS due to their sustained and excessive training [51], also overtraining could be interpreted as a form of self-harm in that it may be that overtraining served the function of a cry for help and a maladaptive attempt to communicate internal distress [35].

The extreme of OTS is burnout, which has been reported in approximately $10 \%$ of elite athletes [50]. When an athlete is over trained, their motivation remains, although when athletes suffer from burnout, they typically experience chronic fatigue, poor sleep patterns, episodes of depression and helplessness [52]. It is therefore not surprising that their performance is negatively affected.

\section{Disordered Eating}

Disordered eating occurs on a continuum ranging from dieting and restrictive eating at one end, to abnormal eating behaviour, and clinical eating disorders at the other end of the continuum [53]. Male elite athletes are more vulnerable to eating disorders than males in the general population $[54,55]$. A study on dieting and disordered eating found that $59 \%$ of the young male elite athletes were dissatisfied with their body, 19\% were dieting and $11 \%$ had disordered eating [56]. The prevalence of disordered eating was $10 \%, 17 \%$ and $42 \%$ for endurance, weight class and antigravitations sports, respectively [56].

Elite athletes often embody the concept of physical perfection and they can often experience pressure to achieve an 'ideal' body type [57], and they can experience the stress of constantly denying hunger, obsessing about food, agonising over body weight and fearing high body weight which can be mentally exhausting.

Symptoms of eating disorders can occur more frequently in sports where low body weight enhances performance, which are subdivided in weight classes or in which weight is advantageous [58]. Elite athletes involved in weight-sensitive sports are at greater risk of developing eating disorders than the general population [59], and male athletes who compete in weight class sports such as wrestling and rowing are at an increased risk whilst male athletes who compete in swimming and figure skating are at a reduced risk for eating disorders [60]. Body weight is also important in sports where aerodynamics and reduced resistance or drag is important such as cycling and swimming [57]. Male athletes 
do have body anxieties but find it difficult to disclose their health-related concerns [61].

\section{Substance Abuse}

Substance abuse and substance addiction may be a concern within elite sport. Athletes often use substances to assist performance. The reasons they may abuse substances include stress relief, psychological dependence, negative emotions reduction and tolerance/withdrawal [62].

Higher rates of alcohol consumption and binge drinking may occur in athletes [63], and athletes may indulge in risk taking behaviours such as hazardous drinking [64]. Substance abuse amongst elite adolescent athletes and alcohol consumption is a cause for concern and binge drinking was performed by every third male athlete [65]. Current athletes consume more alcohol than non-athletes and alcohol consumption was more common amongst team sports athletes than other sports [66]. Cannabis appears to be the second most widely used drug after alcohol, although many elite athletes deny its use [67]. Men are more likely to use cannabis to improve both sport and non-sport performance [68], and male adolescents participating in organised sports are more likely to abuse opioids compared with both non-athlete peers and females [69]. Elite athletes may also become addicted to stimulants for performance enhancement, although they may be a range of adverse effects including anxiety, insomnia, irritability and weight loss [70]. Risk taking behaviour such as gambling within elite athletes is currently under-researched; however, gambling is widespread amongst professional athletes with at least $56 \%$ having gambled at least once in the previous year, which is much greater than the general population across Europe [71]. Anecdotal evidence suggests that gambling addiction is particularly problematic within professional football; however, further research needs to be commissioned to understand the issues in greater detail.

\section{Help Seeking}

It is clear from the literature that elite male athletes do experience a range of common mental disorders and stressors that are either created externally or internally. However, it appears that athletes prefer to discuss their issues or talk publicly after their elite career has ended. This is supported by the large number of sporting autobiographies released each year. A factor behind this reluctance to discuss issues during their playing career could be related to the stigma around mental health. Stigma has been highlighted as a barrier to help seeking in athletes [10]. The prevalence of common mental disorders in elite sport is underreported because of stigma [72]. There is a view that athletes who do seek help for psychological problems may be seen as weak by other athletes and coaches [73]; however, it is important to highlight that it is okay for men to talk about problems and feelings-it should not be seen as a sign of weakness, rather it is a strength [74].

A focus group study found that athletes would be worried about others finding out if they were seeking help for a mental health problem [10]. Stigma could be seen as a strategy to protect one's survival in the team, as well as to cast out individuals who threatened the team's success [75]. Athletes are used to being in the spotlight and may have 'situational narcissism' which can make it difficult for them to seek or accept assistance [76]. They also suggest that athletes may not easily discuss their emotions as they have been taught to work through pain.

There is starting to be a shift in help-seeking attitudes within elite sport. As previously mentioned, Cricket have put an emphasis upon player welfare as have Rugby League in particular. Rugby League in conjunction with National Health Service (NHS) professionals created State of Mind Sport (SOMS) followed the death of Terry Newton, an international rugby league player. SOMS has been supported by the Time to Change campaign, Mind, the Samaritans and the suicide prevention charity PAPYRUS, which has enabled former players to access their training programmes [74]. The supportive work that cricket and rugby are doing to break down barriers and challenge stigma are an important influence upon this review.

\section{Mental Toughness}

To understand mental health in elite sport, it is worth considering the concept of mental toughness and how that may impact upon an athlete. There is a belief that mental toughness and mental health are contradictory in elite sport [17]. The stigma regarding seeking help may jeopardise an athlete's place in the team or their contract to compete. Therefore, seeking help to get better may have a detrimental effect in an athlete's sporting role. Athletes were asked to define mental toughness in their own words and found that mental toughness provided the performer a psychological advantage over their opponents [77]. They also found that mentally tough performers consistently remained determined, focused, confident and in control of the pressures and demands of their sport. Mental toughness may represent a positive indicator of mental health, or facilitate its attainment, rather than be at odds with it [78]. Athletes and coaches may show an interest in programs that are termed mental toughness development in order to engage in discussions around mental health. State of Mind Sport have developed sessions for rugby players and used the language of 'mental fitness' to draw them in [74]. 
In terms of football, coaches were united in the notion that mental toughness is a key ingredient to a successful sporting career [79]. This was expressed in the notion that 'It's the difference between making or breaking careers', and a significant influencer of team selection. Communication is important in mental toughness; mentally tough players would communicate positively by encouraging and activating their teammates, whereas negative communication either towards oneself, teammates or opponents were indicated as a sign of mental weakness [80]. Mentally tough academy players had a desire to achieve, a love for the sport alongside a commitment to excellence that translated passion into success [81].

\section{Conclusion}

Major negative life events, including injury, may increase the risk of mental ill-health in elite athletes [6]. They are vulnerable to profession-specific stressors as well as life events similar to the general population. Although male athletes will discuss psychological issues whilst they are undergoing treatment for injury, more work needs to be done to encourage them to open up and discuss their emotions, concerns and anxieties. Male athletes are under constant performance pressure in relation to the sport, although the literature suggests that they do not prioritise their emotional wellbeing. Many of them also have the additional pressure of living their life in the public eye which can be an additional challenge that some athletes are not used to. It can become a vicious circle when men suffer emotionally, it can impact on their personal and sporting life; this can then lead to performance issues and in turn increase their injury risk. And as the literature suggests, injuries can then increase the risk of mental health issues and adverse behaviours. Although there are a number of help-seeking campaigns particularly supported on social media, there should be further education and awareness of mental health issues aimed at elite male athletes. Male athletes cannot be mentally tough all of the time but if they are supported and encouraged to seek help and share their experiences, this will significantly improve their mental fitness and give them a greater sense of emotional wellbeing.

\section{Abbreviations}

CTE: Chronic traumatic encephalopathy; NFL: National Football League; NHS: National Health Service; OTS: Overtraining syndrome; PCA: Professional Cricketer's Association; SOMS: State of mind sport; UK: United Kingdom; US: United States

\section{Acknowledgements}

N/A

\section{Funding}

No financial support was received for the conduct of this review or preparation of this manuscript.
Availability of Data and Materials

Data sharing not applicable to this article as no datasets were generated or analysed during the current study.

\section{Authors' Contributions}

Gary Souter is the lead author and this article is part of an ongoing PhD project. Robin Lewis and Laura Serrant are the PhD supervisors and have contributed, advised reviewed and supported the study. All authors read and approved the final manuscript.

\section{Ethics Approval and Consent to Participate}

$\mathrm{N} / \mathrm{A}$

\section{Consent for Publication}

N/A

\section{Competing Interests}

The authors, Gary Souter, Robin Lewis, and Laura Serrant, declare that they have no competing interests.

\section{Publisher's Note}

Springer Nature remains neutral with regard to jurisdictional claims in published maps and institutional affiliations.

\section{Author details}

${ }^{1}$ Sheffield Hallam University, Faculty of Health \& Wellbeing, F426 Robert Winston Building, 11-15 Broomhall Road, Sheffield S10 2BP, UK. ${ }^{2}$ Sheffield Hallam University, Faculty of Health \& Wellbeing, M104 Mundella House, 34 Collegiate Crescent, Sheffield S10 2BP, UK. ${ }^{3}$ Manchester Metropolitan University, Brooks Building Manchester Campus, Manchester, UK.

Received: 30 May 2018 Accepted: 3 December 2018

Published online: 19 December 2018

\section{References}

1. Carr C. Sport psychology: psychologic issues and applications. Phys Med Rehabil Clin N Am. 2006;17(3):519-35.

2. Glick I, Castaldelli-Maia J. Sport psychiatry 2016: brain, mind, and medicalpsychiatric care. Int Rev Psychiatry. 2016;28(6):545-6.

3. MIND. (2017). How to improve your mental wellbeing. Retrieved from https://www.mind.org.uk/information-support/tips-for-everyday-living/ wellbeing/wellbeing/?o=10135\#.WelUOq3My1s (accessed 3 Jan 2018).

4. National Institute for Clinical Excellence. Common mental health problems: identification and pathways to care clinical guideline. London: NICE; 2011.

5. Wolanin A, Gross M, Hong E. Depression in athletes: prevalence and risk factors. Curr Sports Med Rep. 2015;14(1):56-60.

6. Rice $S$, Purcell $R$, Silva $S$, et al. The mental health of elite athletes: a narrative systematic review. Sports Med. 2016;46(9):1333-53.

7. Gulliver A, Griffiths K, Mackinnon A, et al. The mental health of Australian elite athletes. J Sci Med Sport. 2015;18(3):255-61. http://dx.doi.org.Icproxy. shu.ac.uk/10.1016/j.jsams.2014.04.006.

8. Gouttebarge V, Aoki H, Ekstrand J, et al. Are severe musculoskeletal injuries associated with symptoms of common mental disorders among male european professional footballers? Knee Surg Sports Traumatol Arthrosc. 2016;24(12):3934-42. https://doi.org/10.1007/s00167-015-3729-y.

9. Gouttebarge V, Aoki H, Kerkhoffs G. Prevalence and determinants of symptoms related to mental disorders in retired male professional footballers. J Sports Med Phys Fitness. 2015; 56(5):648-654

10. Gulliver A, Griffiths K, Christensen H. Barriers and facilitators to mental health help-seeking for young elite athletes: a qualitative study. BMC Psychiatry. 2012;12:157.

11. Didehbani N, Cullum C, Mansinghani S, et al. Depressive symptoms and concussions in aging retired NFL players. Arch ClinNeuropsychol. 2013;28(5): 418-24. http://dx.doi.org.lcproxy.shu.ac.uk/10.1093/arclin/act028.

12. Kerr Z, Marshall S, Harding H, et al. Nine-year risk of depression diagnosis increases with increasing self-reported concussions in retired professional football players. Am J Sports Med. 2012:40:2206-12.

13. Guskiewicz K, Marshall S, Bailes J, et al. Recurrent concussion and risk of depression in retired professional football players. Med Sci Sports Exerc. 2007;39(6):903-9. 
14. Mez J, Daneshvar D, Kiernan P, et al. Clinicopathological evaluation of chronic traumatic encephalopathy in players of American football. JAMA. 2017;318(4):360-70. https://doi.org/10.1001/jama.2017.8334.

15. Nixdorf I, Frank R, Hautzinger $M$, et al. Prevalence of depressive symptoms and correlating variables among German elite athletes. J Clin Sport Psychol. 2013;7(4):313-26.

16. Arnold R, Fletcher D. A research synthesis and taxonomic classification of the organisational stressors encountered by sports performers. J Sport Exerc Psychol. 2012;34:397-429. https://doi.org/10.1123/jsep.34.3.397.

17. Bauman $\mathrm{N}$. The stigma of mental health in athletes: are mental toughness and mental health seen as contradictory in elite sports? Br J Sports Med. 2016:50(3):135-6. https://doi.org/10.1136/bjsports-2015-095570.

18. Noblet A, Gifford S. The sources of stress experienced by professional Australian footballers. J Appl Sport Psychol. 2002;14:1-13.

19. Newman $H$, Howells $K$, Fletcher D. The dark side of top level sport: an autobiographic study of depressive experiences in elite sport performers. Front Psychol. 2016;7:868. https://doi.org/10.3389/fpsyg.2016.00868.

20. Lally P. Identity and athletic retirement: a prospective study. Psychol Sport Exerc. 2007;8:85-99.

21. North J, Lavallee D. An investigation of potential users of career transition services in the United Kingdom. Psychol Sport Exerc. 2004;5:77-84.

22. Burns $G$, Jasinski $D$, Dunn $S$, et al. Athlete identity and athlete satisfaction: the nonconformity of exclusivity. Pers Individ Dif. 2012;52:280-4

23. Martin L, Fogarty G, Albion M. Changes in athletic identity and life satisfaction of elite athletes as a function of retirement status. J Appl Sport Psychol. 2014;26(1):96-110.

24. Grove J, Lavallee D, Gordon S. Coping with retirement from sport: the influence of athletic identity. J Appl Sport Psychol. 1997;9(2):191-203.

25. Brown C, Webb T, Robinson M, et al. Athletes' experiences of social support during their transition out of elite sport: an interpretive phenomenological analysis. Psychol Sport Exerc. 2018;36:71-80

26. Shah A, Sava-Shah S, Wijeratne C, et al. Are elite cricketers more prone to suicide? A psychological autopsy study of test cricketer suicides. Australas Psychiatry. 2016;24(3):295-9. http://dx.doi.org.lcproxy.shu.ac.uk/10.1177/ 1039856216641311.

27. Professional Cricketers Association (2018). Benevolent fund news. Retrieved from https://www.thepca.co.uk/news/benevolent-fund/

28. Schuring N, Kerkhoffs G, Gray J, et al. The mental wellbeing of current and retired professional cricketers: an observational prospective cohort study. The Phys Sportsmed. 2017; https://doi.org/10.1080/00913847.2017.1386069.

29. Weigand S, Cohen J, Merenstein D. Susceptibility and depression in current and retired student athletes. Sports Health. 2013;5:263-6. https://doi.org/10. 1177/1941738113480464

30. Jones $M$, Sheffield $D$. The impact of game outcome on the well-being of athletes. Int J Sport Nutr Exerc Metab. 2008:5:54-65. https://doi.org/10.1080/ 1612197X.2008.9671812.

31. Nicholls A, Polman R, Levy A, et al. Stressors, coping and coping effectiveness: gender, type of sport, and skill differences. J Sport Sci. 2007; 25(13):1521-30. https://doi.org/10.1080/02640410701230479.

32. Mummery K. Essay- depression in sport. Lancet. 2005;366:S36-7.

33. Howells K, Fletcher D. Sink or swim: adversity- and growth-related experiences in Olympic swimming champions. Psychol Sport \& Exerc. 2015; 16:37-48. https://doi.org/10.1016/j.psychsport.2014.08.004

34. Frank R, Nixdorf I, Beckmann J. Depression among elite athletes: prevalence and psychological factors. German J Sport Med. 2013:64:320-6.

35. Doherty S, Hannigan B, Campbell M. The experience of depression during the careers of elite male athletes. Front Psychol. 2016;7:1069.

36. Hammond T, Gialloretto C, Kubas $\mathrm{H}$, et al. The prevalence of failure-based depression among elite athletes. Clin J Sport Med. 2013;23:273-7. https:// doi.org/10.1097/JSM.0b013e318287b870.

37. Yang J, Peek-Asa C, Corlette J, et al. Prevalence of and risk factors associated with symptoms of depression in competitive collegiate student athletes. Clin J Sport Med. 2007;17(6):481-7.

38. Neil R, Wilson K, Mellalieu S, et al. Competitive anxiety intensity and interpretation: a two-study investigation into their relationship with performance. Int J Sport Exerc Psychol. 2012;10(2):96-111.

39. Gardner L, Vella S, Magee C. The relationship between implicit beliefs, anxiety, and attributional style in high-level soccer players. J Appl Sport Psychol. 2015;27:398-411.

40. Baghurst T. The psychological components of elite cycling. Athletic Insight. 2012;4(1):13-29.
41. Hanton S, Wadey R, Connaughton D. Debilitative interpretations of competitive anxiety: a qualitative examination of elite performers. Eur J Sport Sci. 2005;5(3):123-36.

42. Lundqvist C, Kentta G, Raglin J. Directional anxiety responses in elite and sub-elite young athletes: intensity of anxiety symptoms matters. Scand J Med Sci Sports. 2011:21:853-62.

43. Jensen S, Ivarsson A, Fallby J, et al. Depression in Danish and Swedish elite football players and its relation to perfectionism and anxiety. Psychol Sport Exerc. 2018;36:147-55

44. Junge A, Feddermann-Demont N. Prevalence of depression and anxiety in top-level male and female football players. BMJ Open Sport Exerc Med. 2016;2(1):e000087. https://doi.org/10.1136/bmjsem-2015-000087.

45. Du Preez E, Graham K. Depression, anxiety, and alcohol use in elite rugby league players over a competitive season. Clin J Sport Med. 2017;27(6):530-5.

46. Rice S, Parker A, Rosenbaum S, et al. Sport-related concussion and mental health outcomes in elite athletes: a systematic review. Sports Med. 2018:48:447-65.

47. Meeusen R, Duclos M, Foster C, et al. Prevention, diagnosis and treatment of the overtraining syndrome: joint consensus statement of the European college of sport science (ECSS) and the American college of sports medicine (ACSM). Eur J Sport Sci. 2013;13(1):1-24.

48. Armstrong $L$, VanHeest J. The unknown mechanism of the overtraining syndrome: clues from depression and psychoneuroimmunology. Sports Med. 2002;32:185-209.

49. Birrer D, Lienhard D, Williams C, et al. Prevalence of non-functional overreaching and the overtraining syndrome in swiss elite athletes. Schweizerische Zeitschrift Für Sportmedizin \& Sporttraumatologie. 2013;61(4):23-9.

50. Peluso $M$, deAndrade L. Physical activity and mental health: the association between exercise and mood. Clinics. 2005;60:61-70.

51. Bär K, Markser V. Sport specificity of mental disorders: the issue of sport psychiatry. Eur Arch Psychiatry and Clin Neurosci. 2013;263:S205-10. http:// dx.doi.org.lcproxy.shu.ac.uk/10.1007/s00406-013-0458-4.

52. Lemyre P, Roberts C, Stray-Gundersen J. Motivation, overtraining, and burnout: can self-determined motivation predict overtraining and burnout in elite athletes? Eur J Sport Sci. 2007;7(2):115-26.

53. McArdle S, Meade M, Moore P. Exploring attitudes toward eating disorders among elite athlete support personnel. Scand J Med Sci Sports. 2016;26: 1117-27.

54. Baum A. Eating disorders in the male athlete. Sports Med. 2006;36(1):1-6.

55. Riebl S, Subudhi A, Broker J, et al. The prevalence of subclinical eating disorders among male cyclists. J Am Diet Assoc. 2007;107(7):1214-7.

56. Rosendahl J, Bormann B, Aschenbrenner K, et al. Dieting and disordered eating in German high school athletes and non- athletes. Scand J Med Sci Sports. 2009;19(5):731-9.

57. Sundgot-Borgen J, Torstveit M. Aspects of disordered eating continuum in elite high-intensity sports. Scand J Med Sci Sports. 2010;20:112-21.

58. Strohle A. Sports psychiatry: mental health and mental disorders in athletes and exercise treatment of mental disorders. Eur Arch Psychiatry Clin Neurosci. 2018; https://doi.org/10.1007/s00406-018-0891-5.

59. Bar R, Cassin S, Dionne M. Eating disorder prevention initiatives for athletes: a review. Eur J Sport Sci. 2016;16(3):325-35.

60. Sundgot-Borgen J, Torstveit MK. Prevalence of eating disorders in elite athletes is higher than in the general population. Clin J Sports Med. 2004; 14(1):25-32

61. Darko N. "Get up, shut up and stop being a fanny": Rugby union men and their suppression of body anxiety. J Mens Health. 2009;6(4):331-7. http://dx. doi.org.lcproxy.shu.ac.uk/10.1016/j.jomh.2009.09.001.

62. Morse E. Substance use in athletes. In: Clinical sports psychiatry. Oxford: Wiley; 2013. p. 1-12.

63. Dietze P, Fitzgerald J, Jenkinson R. Drinking by professional australian football league (AFL) players: prevalence and correlates of risk. Med J Aust. 2008:189(9):479.

64. Hughes L, Leavey G. Setting the bar: athletes and vulnerability to mental illness. Br J Psychiatry. 2012;200(2):95-6. http://dx.doi.org.lcproxy.shu.ac.uk/ 10.1192/bjp.bp.111.095976.

65. Diehl K, Thiel A, Zipfel S, et al. Substance use among elite adolescent athletes: findings from the GOAL study. Scand J Med Sci Sports. 2012;24(1): 250-8. https://doi.org/10.1111/j.1600-0838.2012.01472x.

66. Kontro T, Sarna S, Kaprio J, et al. Use of alcohol and alcohol-related morbidity in finnish former elite athletes. Med Sci Sports Exerc. 2017:47(3): 492-9. https://doi.org/10.1249/MSS.0000000000001137. 
67. Briscola-Santos M, Gallinaro J, Gil F, et al. Prevalence and correlates of cannabis use among athletes - a systematic review. Am J Addic. 2016;25:518-28.

68. Lorente F, Peretti-Watel P, Grelot L. Cannabis use to enhance sportive and non-sportive performances among French sport students. Addic Behav. 2005;30:1382-91.

69. Gil F, de Andrade A, Castaldelli-Maia J. Discussing prevalence, impacts, and treatment of substance use disorders in athletes. Int Rev Psychiatry. 2016; 28(6):572-8.

70. Reardon C, Factor R. Sports psychiatry: a systematic review of diagnosis and medical treatment of mental illness in athletes. Sports Med. 2010;40(11):961-80.

71. Grall-Bronnec M, Caillon J, Humeau E, et al. Gambling among European professional athletes. prevalence and associated factors. J Addict Dis. 2016;35(4):278-90. http://dx.doi.org.lcproxy.shu.ac.uk/10.1080/10550887. 2016.1177807.

72. Roberts C, Faull A, Tod D. Blurred lines: performance enhancement, common mental disorders and referral in the UK athletic population. Front in Psychol. 2016;7:1067. https://doi.org/10.3389/fpsyg.2016.01067.

73. Watson J. College student-athletes' attitudes toward help-seeking behaviour and expectations of counselling services. J Coll Stud Dev. 2005:46(4):442-9.

74. Rae M, Cooper P, Johnston A. Tackling stigma through sport. Ment Health Pract. 2016;20(4):14-7.

75. DeLenardo S, Terrion J. Suck it up: opinions and attitudes about mental illness stigma and help-seeking behaviour of male varsity football players. Can J Commun Ment Health. 2014;33(3):43-56. http://dx.doi.org.lcproxy.shu. ac.uk/10.7870/cjcmh-2014-023.

76. Glick I, Stillman M, Reardon C, et al. Managing psychiatric issues in elite athletes. J Clin Psychiatry. 2012;73(5):640-4. http://dx.doi.org.lcproxy.shu.ac. uk/10.4088/JCP.11r07381

77. Jones $\mathrm{G}$, Hanton S, Connaughton D. What is this thing called mental toughness? An investigation of elite sports performers. J Appl Sport Psychol. 2002;14(3):205-18.

78. Gucciardi D, Hanton S, Fleming S. Are mental toughness and mental health contradictory concepts in elite sport? A narrative review of theory and evidence. J Sci Med Sport. 2017;20(3):307-11. https://doi.org/10.1016/j.jsams. 2016.08.006

79. Owusu-Sekyere F, Gervis M. In the pursuit of mental toughness: is creating mentally tough players a disguise for emotional abuse? Int J Coach Sci. 2016;10(1):3-23.

80. Diment G. Mental toughness in soccer: a behavioural analysis. J Sport Behav. 2014;37(4):317-31.

81. Cook C, Crust L, Littlewood M, et al. "what it takes": perceptions of mental toughness and its development in an english premier league soccer academy. Qual Res Sport Exerc Health. 2014;6(3):329-47. https://doi.org/10 1080/2159676X.2013.857708

\section{Submit your manuscript to a SpringerOpen ${ }^{\circ}$ journal and benefit from:}

- Convenient online submission

- Rigorous peer review

- Open access: articles freely available online

- High visibility within the field

- Retaining the copyright to your article

Submit your next manuscript at $\boldsymbol{\nabla}$ springeropen.com 